\title{
Insulin resistance in offspring of hypertensive parents
}

\author{
Olivia L Beatty, Roy Harper, Brian Sheridan, A Brew Atkinson, Patrick M Bell
}

\begin{abstract}
Objective-To determine if insulin resistance is present in normotensive adults at increased risk of developing hypertension.

Design-Normotensive subjects with at least one hypertensive parent were paired with offspring of normotensive parents (controls), being matched for age, sex, social class, and physical activity.
\end{abstract}

Setting-Outpatient clinic.

Subjects-30 paired subjects (16 men and 14 women) with and without a family history of hypertension, aged 18-32, with a body mass index $<25 \mathrm{~kg} / \mathrm{m}^{2}$, with blood pressure $<130 / 85 \mathrm{~mm} \mathrm{Hg}$, and not taking drugs.

Interventions-Euglycaemic glucose clamp (two hour infusion of insulin $1 \mathrm{mU} / \mathrm{kg} / \mathrm{min}$ ) and intravenous glucose tolerance test (injection of $100 \mathrm{ml}$ $20 \%$ glucose).

Main outcome measures-Insulin mediated glucose disposal and insulin secretion.

Results-The offspring of hypertensive parents had slightly higher blood pressure than did the controls (mean 117 (SD 6) $v 108$ (5) $\mathrm{mm} \mathrm{Hg}$ systolic, $\mathrm{p}=0.013 ; 76$ (7) $v 67$ (6) $\mathrm{mm} \mathrm{Hg}$ diastolic, $p=0.017)$. Their insulin mediated glucose disposal was lower than that of controls $(29.5(6.5) v 40.1$ (8.6) $\mu \mathrm{mol} / \mathrm{kg} / \mathrm{min}, p=0.002)$, but, after adjustment for blood pressure, the difference was not significant (difference $6.9(95 \%$ confidence interval -1.5 to $15 \cdot 3), p=0 \cdot 10)$. Insulin secretion in the first hour after injection of glucose was slightly but not significantly higher in the offspring of hypertensive patients $(9320(5484) v 6723(3751) \mathrm{pmol} . \mathrm{min} / \mathrm{l})$. The two groups had similar concentrations of plasma glucose $(5.2(0.3) v 5.1(0.4) \mathrm{mmol} / \mathrm{l})$, serum cholesterol $(4.4(0.8) v 4.6(0.8) \mathrm{mmol} / \mathrm{l})$, serum triglyceride $(0.89(0.52)$ v $0.68(0.27) \mathrm{mmol} / \mathrm{l})$, and serum low density lipoprotein cholesterol $(2.81(0.65) v$ $2.79(0.61) \mathrm{mmol} / \mathrm{/})$. The offspring of hypertensive parents, however, had lower serum concentrations of high density lipoprotein cholesterol $(1.24(0.31) v$ $1.56(0.35) \mathrm{mmol} / \mathrm{h}, \mathrm{p}=0.002)$ and higher serum concentrations of non-esterified fatty acids $(0.7(0.4)$ $v 0.4(0.4) \mathrm{mmol} / \mathrm{p}=0.039)$.

Conclusions-Young normotensive subjects who are at increased risk of developing hypertension are insulin resistant.

Metabolic Unit, Royal

Victoria Hospital, Belfast BT12 6BA

Olivia L Beatty, research

fellow

Roy Harper, research fellow

A Brew Atkinson, consultant physician

Patrick M Bell, consultant

physician

Regional Endocrine Laboratory, Royal Victoria Hospital

Brian Sheridan, principal biochemist

Correspondence to: Dr Bell.

BMF 1993;307:92-6

\section{Introduction}

Evidence from epidemiological and clinical studies indicates that essential hypertension is associated with insulin resistance and that this is independent of obesity, glucose tolerance, and age. ${ }^{1-3}$ One explanation for the association is that some feature of essential hypertension causes insulin resistance: obvious candidates are the commonly used antihypertensive drugs, especially thiazide diuretics and $\beta$ adrenergic blockers. ${ }^{4-6}$ The presence of impaired insulin action in relatively young, untreated patients, however, argues against antihypertensive medication being the sole aetiological factor in insulin resistance. ${ }^{78}$ Alternatively, insulin resistance (and associated hyperinsulinaemia) may cause raised blood pressure: suggested mechanisms include insulin inducing increased renal tubular reabsorption of sodium and release of pressor hormones. ${ }^{9-11}$ If insulin resistance comres first, what determines a person's degree of insulin sensitivity?

In order to investigate these issues we made use of the observation that offspring of hypertensive parents are more likely to develop hypertension than offspring of normotensive parents. ${ }^{12-14}$ By examining insulin action in groups of such offspring, themselves normotensive, we hoped to establish whether insulin resistance precedes clinical hypertension. The presence of impaired insulin action in a group with a familial predisposition to essential hypertension would raise the possibility that insulin resistance is also determined as a familial trait, which could be important in the pathogenesis of subsequent hypertension.

\section{Subjects and methods}

Potential subjects for the study were identified from records of three suburban general practices in greater Belfast. Subjects were considered eligible if they were aged 18-32, their body mass index ((weight $(\mathrm{kg}) /$ (height) $(\mathrm{m}))^{2}$ ) was $<25$, their blood pressure was $<130 / 85 \mathrm{~mm} \mathrm{Hg}$ (to be below the mean + one SD blood pressure of the population of greater Belfast ${ }^{15}$ ), and they were not taking any drugs. Subjects with uncertainty about a family history of hypertension and those with a family history of diabetes mellitus in any first degree relative were excluded.

Information on the blood pressure of hypertensive parents was obtained, with their consent, from general practice records. Hypertensive parents were defined as those who had a blood pressure $>160 / 95 \mathrm{~mm} \mathrm{Hg}$ on two occasions before receiving antihypertensive treatment and for whom there was no evidence to suggest secondary forms of hypertension, but since these patients had been managed in general practice, detailed investigations had not been carried out. The mean (SD) untreated blood pressure of the hypertensive parents (aged 45-65) was 177 (19)/108 (8) $\mathrm{mm} \mathrm{Hg}$ Normal blood pressure in the normotensive parents was defined as $<140 / 90 \mathrm{~mm} \mathrm{Hg}$ on two occasions in both parents. This information was obtained from general practice records or, when this was unavailable, blood pressure was measured by one of the investigators. In the normotensive parents mean (SD) current blood pressures were $126(13) / 77(8) \mathrm{mm} \mathrm{Hg}$ in the mothers and $125(14) / 68(11) \mathrm{mm} \mathrm{Hg}$ in the fathers.

Fifteen pairs of subjects (16 men and 14 women)

were identified who were carefully matched for age and sex and broadly matched for physical activity (allowing a difference of one band ${ }^{16}$ ) and social class (allowing a difference of one category). Physical activity at work and leisure in the four weeks before the test was assessed by a simple self reporting questionnaire. All the subjects were non-smokers. Of the subjects who had hypertensive parents, 13 had one parent with hypertension and two had both parents with hypertension. Written consent was obtained from each subject for participation in the clinical studies.

Euglycaemic hyperinsulinaemic glucose clamps and 
intravenous glucose tolerance tests were performed for each subject at least one week apart. For three days before each test the subjects' diets contained at least $150 \mathrm{~g}$ carbohydrate daily. Women were studied in the first 10 days of their menstrual cycle to avoid variation in insulin sensitivity at different times of the cycle. ${ }^{17}$ Systolic and diastolic blood pressure was measured in triplicate after at least 10 minutes in the supine position with a Hawksley random zero sphygmomanometer.

Insulin sensitivity was determined with the euglycaemic glucose clamp technique. ${ }^{8}$ Briefly, the subjects were admitted to our unit at $800 \mathrm{am}$ after an overnight fast of 10 hours. A plastic 18 French gauge cannula (Venflon, Viggo, Helsinborg, Sweden) was inserted into a left antecubital vein for infusions, and this was quickly followed by a 21 French gauge cannula (Venflon, Viggo) inserted retrogradely into a dorsal vein of the right hand. This was maintained at $55^{\circ} \mathrm{C}$ in a thermostatically controlled Perspex enclosure (Automaton Division, Ashby Institute, Queen's University of Belfast). Basal (fasting) blood samples were then collected for determination of plasma glucose, serum insulin, serum lipids, free fatty acids, glycerol, and $\beta$-hydroxybutyrate. After 25 minutes' rest to re-establish basal conditions, insulin (Humulin $S$, Eli Lilly, Basingstoke) was administered at $1.0 \mathrm{mU} / \mathrm{kg} / \mathrm{min}$ for two hours. Arterialised blood samples were obtained at five minute intervals for estimation of plasma glucose. The samples were centrifuged immediately at the bedside and analysed with a glucose oxidase method (Beckman Glucose Analyser II, Beckman RIIC, High Wycombe). Plasma glucose concentration was maintained at the fasting level by a variable exogenous infusion of $20 \%$ glucose solution. During the last 30 minutes of the clamp the rates of glucose infusion were corrected for slight variations from target plasma glucose to give an estimate of overall insulin mediated glucose disposal. ${ }^{18}$ Blood samples for determination of insulin, free fatty acids, glycerol, and $\beta$-hydroxybutyrate were collected in plain glass tubes. Samples were separated as soon as clotting was complete and were stored at $-20^{\circ} \mathrm{C}$ until analysis.

Intravenous glucose tolerance tests were performed with 13 pairs of subjects (two subjects were unable to reattend), who were admitted at 800 am after an overnight fast of 10 hours. An intravenous cannula was placed in an antecubital vein for blood sampling. An injection of $20 \mathrm{~g}$ glucose $(100 \mathrm{ml}$ of $20 \%$ solution) was given rapidly, and blood samples were taken at $2,4,6$, $8,10,20,40$, and 60 minutes after injection for estimation of plasma glucose and insulin. Plasma glucose was analysed at the bedside as described above.

Serum insulin was determined by a radioimmunoassay with insulin antibody precipitate. ${ }^{19}$ Commercial kits were used to estimate serum non-esterified free fatty acid (interassay coefficient of variation $4 \cdot 2 \%$ ) (Wako Chemicals, Neuss, Germany), $\beta$-hydroxybuty-

Characteristics of offspring of hypertensive and normotensive parents. Figures are means (standard deviations) unless stated otherwise

\begin{tabular}{|c|c|c|c|}
\hline & $\begin{array}{l}\text { Children of } \\
\text { hypertensive } \\
\text { parents } \\
(n=15)\end{array}$ & $\begin{array}{c}\text { Children of } \\
\text { normotensive } \\
\text { parents } \\
(n=15)\end{array}$ & $\begin{array}{c}\text { Mean difference } \\
(95 \% \text { confidence interval) }\end{array}$ \\
\hline Age :years) & $25.8(3.9)$ & $25.7(3.9)$ & \\
\hline Body mass index $\left(\mathrm{kg} / \mathrm{m}^{2}\right)$ & $22 \cdot 8(2 \cdot 3)$ & $22 \cdot 4(1.5)$ & $0.4(-0.9$ to 1.7$)$ \\
\hline \multicolumn{4}{|l|}{ Blood pressure $(\mathrm{mm} \mathrm{Hg})$ : } \\
\hline Systolic & $117(6)$ & $108(5)^{\star}$ & 8 (3 to 14$)$ \\
\hline Diastolic & $76(7)$ & $67(6)^{\star}$ & $9(3$ to 15$)$ \\
\hline \multicolumn{4}{|l|}{ Serum concentration $(\mathrm{mmol} / \mathrm{l})$ : } \\
\hline Cholesterol & $4 \cdot 4(0 \cdot 8)$ & $4 \cdot 6(0 \cdot 8)$ & $-0.2(-0.88$ to 0.42$)$ \\
\hline Triglyceride & $0.89(0.52)$ & $0 \cdot 68(0 \cdot 27)$ & $0.20(-0.04$ to 0.45$)$ \\
\hline Low density lipoprotein cholesterol & $2.81(0.65)$ & $2 \cdot 79(0.61)$ & $0.02(-0.47$ to 0.49$)$ \\
\hline High density lipoprotein cholesterol & $1.24(0.31)$ & $1.56(0.35)^{\star \star}$ & $-0.32(-0.51$ to -0.12$)$ \\
\hline
\end{tabular}

\section{Results}

The table shows that the offspring of hypertensive parents had slightly higher blood pressures, systolic $(p=0.013)$ and diastolic $(p=0.017)$, than those of the control group (offspring of normotensive parents). The serum concentrations of cholesterol, triglyceride, and low density lipoprotein cholesterol did not differ significantly between the groups, but that of high density lipoprotein cholesterol was lower in the offspring of hypertensive parents $(p=0.002)$. The offspring of hypertensive and normotensive parents had similar fasting concentrations of plasma glucose $(5 \cdot 2(0.3)$ v $5 \cdot 1(0.4) \mathrm{mmol} / \mathrm{l}, \mathrm{p}=0 \cdot 22)$, serum insulin $(41.6(11.1) v 32.3(5.5) \mathrm{pmol} / \mathrm{l}, \mathrm{p}=0.09)$, serum $\beta$ hydroxybutyrate $(0.12(0.11)$ v $0.07(0.07) \mathrm{mmol} / \mathrm{h}$, $(\mathrm{p}=0.22)$, and serum glycerol $(70.6(27 \cdot 1)$ v 57.2 $(30 \cdot 6) \mathrm{mmol} / \mathrm{l}, \mathrm{p}=0 \cdot 27)$, but offspring of hypertensive parents had significantly higher fasting serum non- 


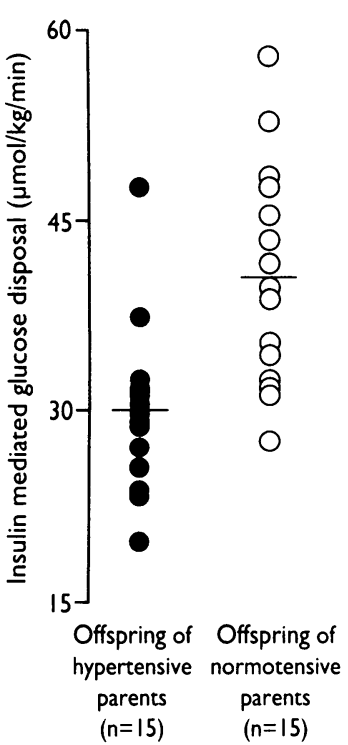

FIG 2-Individual rates of insulin mediated glucose disposal in offspring of hypertensive and normotensive parents esterified free fatty acid concentrations $(0.7(0.4) v$ $0.4(0.4) \mathrm{mmol} / \mathrm{l}, \mathrm{p}=0.039)$.

Figure 1 shows the results of the glucose clamp studies. The mean (SD) plasma glucose concentration and coefficient of variation were $5 \cdot 2(0.3) \mathrm{mmol} / \mathrm{l}$ and $3.9(1.7)$ in the offspring of hypertensive parents and $5 \cdot 1(0 \cdot 2) \mathrm{mmol} / \mathrm{l}$ and $4.3(1.9)$ in the control group. The mean serum insulin concentrations were similar in the two groups $(369.5(119 \cdot 1)$ v $346.5(94.4) \mathrm{pmol} / \mathrm{l}$, $\mathrm{p}=0 \cdot 29$ ). During the last 30 minutes of the glucose clamp insulin mediated glucose disposal was significantly lower among the offspring of hypertensive parents $(29.5(6.6) v 40.1(8.5) \mu \mathrm{mol} / \mathrm{kg} / \mathrm{min})$. The mean difference in glucose disposal was $10.6 \mu \mathrm{mol} / \mathrm{kg} /$ $\min (95 \%$ confidence interval 5.5 to $15 \cdot 7, \mathrm{p}=0 \cdot 002)$. The range of values for glucose disposal was $20 \cdot 7-47 \cdot 3 \mu \mathrm{mol} / \mathrm{kg} / \mathrm{min}$ for the offspring of hypertensive parents and $28.3-57.9 \mu \mathrm{mol} / \mathrm{kg} / \mathrm{min}$ for the control group (fig 2). When the influence of baseline blood pressure was taken into account with simple regression analysis the difference in glucose disposal between the groups was reduced and was no longer significant-after adjustment for systolic blood pressure the mean difference was $6.9(95 \%$ confidence interval $-1 \cdot 5$ to $15 \cdot 3)(p=0 \cdot 10)$, and after adjustment for diastolic blood pressure it was $7 \cdot 1(-2 \cdot 2$ to $-14 \cdot 4)$ $(\mathrm{p}=0 \cdot 06)$.

Serum concentrations of non-esterified free fatty acids, glycerol, and $\beta$-hydroxybutyrate were suppressed equally in both groups during the clamp (fig 3 ).

Figure 4 shows the results of the intravenous glucose tolerance test. After the infusion of glucose, plasma glucose concentrations were similar in both groups. The offspring of hypertensive parents and the control group were also similar in their first phase insulin secretion (area under curve of graph in first 10 minutes) (3049 (1810) v 2597 (1862) pmol.min/l, $\mathrm{p}=0.60)$ and second phase insulin secretion (5761 (3414) $v 4118$ (1914) $\mathrm{pmol} . \mathrm{min} / \mathrm{l}, \mathrm{p}=0 \cdot 32$ ).

\section{Discussion}

Our study demonstrates that insulin resistance is present in young adults who have an increased risk of
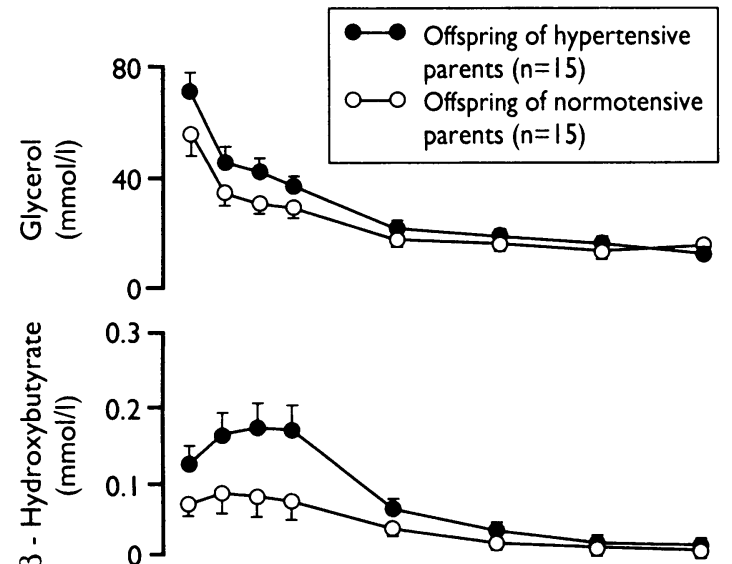

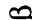

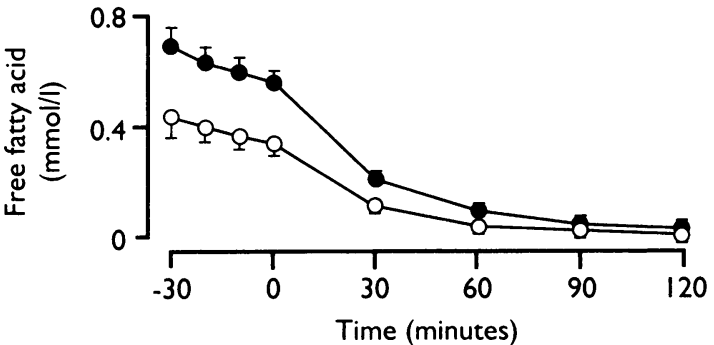

FIG 3-Mean (SE) serum concentrations of glycerol, $\beta$-hydroxybutyrate, and non-esterified free fatty acids in offspring of hypertensive and normotensive parents during euglycaemic glucose clamp. Insulin started at time $O$

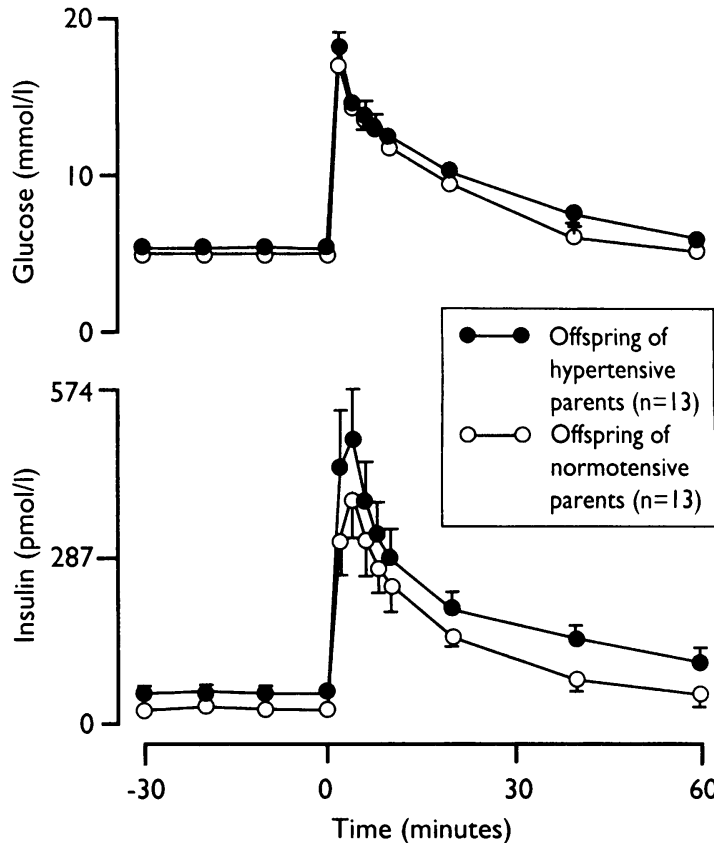

FIG 4-Mean (SE) concentrations of plasma glucose and serum insulin in offspring of hypertensive and normotensive parents during intravenous glucose intolerance test. Glucose givenat time $O$

developing essential hypertension but who are not yet hypertensive. Our subjects were carefully chosen to eliminate other factors which influence insulin resistance, especially obesity, drug treatment, other illness, and a family history of diabetes mellitus. ${ }^{21-23}$ As well as reduced insulin sensitivity, subjects with a parental history of hypertension had raised fasting concentrations of non-esterified fatty acids and reduced concentrations of high density lipoprotein cholesterol. Insulin secretion in response to intravenous glucose was similar in the two groups.

We have previously shown that hepatic insulin sensitivity is normal in hypertensive subjects, and there is general agreement that insulin resistance is located in skeletal muscle. ${ }^{7824}$ Hepatic insulin action was not assessed in the present study, and our observations in the offspring of hypertensive parents can give only an overall measure of insulin action. A possible mechanism of reduced peripheral insulin sensitivity is impaired stimulation of muscle blood flow, which is an important determinant of tissue glucose uptake after administration of insulin. ${ }^{25} 20 \mathrm{No}$ studies, however, have examined skeletal muscle blood flow in essential hypertension. One other group has examined insulin action in people with a hypertensive parent, by means of an intravenous glucose tolerance test: this group also concluded that such people had impaired insulin sensitivity. ${ }^{27}$

Another factor possibly contributing to insulin resistance in our study was increased lipid oxidation: serum non-esterified free fatty acid concentrations were significantly higher in the offspring of hypertensive parents. Increased free fatty acid oxidation due to increased substrate supply leads to impaired oxidation of glucose and the formation of glycogen. ${ }^{28}$

Our results suggest that insulin resistance precedes clinical hypertension. In a study of non-obese subjects (mean age 53) with untreated essential hypertension we found that the mean (SD) infusion rate of exogenous glucose required to maintain euglycaemia during an infusion of insulin $(1 \mathrm{mU} / \mathrm{kg} / \mathrm{min})$ was $27 \cdot 5(9 \cdot 3) \mu \mathrm{mol} /$ $\mathrm{kg} / \mathrm{l}$, compared with $38 \cdot 1(7 \cdot 3) \mu \mathrm{mol} / \mathrm{kg} / \mathrm{l}$ in nonhypertensive controls matched for age $(95 \%$ confidence interval for mean difference 7.8 to $13.4, \mathrm{p}<0.005){ }^{8}$ For the offspring of hypertensive and normotensive parents in the present study the figures were 29.5 (6.5) $\mu \mathrm{mol} / \mathrm{kg} / \mathrm{min}$ and $40.1 \quad(8 \cdot 6) \mu \mathrm{mol} / \mathrm{kg} / \mathrm{min}$ 
respectively. Although we cannot be certain that the offspring of hypertensive parents in the present study will become hypertensive, our data are consistent with the view that a stable degree of insulin resistance may be present for many years before the start of clinical hypertension.

Several theories have been proposed to explain how insulin resistance and consequent hyperinsulinaemia can cause elevated blood pressure. One possible explanation is the effect of hyperinsulinaemia on hormones that regulate blood pressure. We have previously shown that short term physiological hyperinsulinaemia increases the circulating concentrations of renin angiotensin and noradrenaline and increases systolic blood pressure. ${ }^{11}$ Secondly, insulin may promote retention of sodium by the kidney. ${ }^{9}$ Thirdly, insulin is known to have direct and indirect effects on a variety of membrane cation transport systems, particularly sodium-potassium ATPase and sodium-hydrogen exchange..$^{29}$ Even relatively small increases in insulin might initiate the processes outlined above.

In our subjects, however, a minor increase of blood pressure was already present at the time of study, and when differences in insulin action were adjusted for blood pressure they were no longer significant. It is therefore possible that insulin resistance arose after these minor elevations of blood pressure, perhaps through haemodynamically induced alterations to the microcirculation, leading to reduced blood flow and glucose uptake. ${ }^{30}$

The familial connection with insulin resistance suggested by our results is intriguing. The predisposition to elevated blood pressure in people with a parental history of hypertension is already well established, although it is likely to be multifactorial with about $5-10 \%$ of the overall variance in blood pressure being due to the shared family environment. ${ }^{12-1431}$ Current data suggest that more than half of those with essential hypertension will have at least one other first degree relative with hypertension. ${ }^{12}$ We also know that insulin sensitivity varies widely in normal subjects, ${ }^{32} 33$ and it may be determined as a familial characteristic. ${ }^{34} 35$ Insulin resistance being present in offspring of hypertensive parents is consistent with it being a familially determined pathogenetic mechanism for development of hypertension. There are many possible sites for genetic control of insulin resistance including the insulin gene, the insulin receptor gene, and the glucose transporter gene. All have been subjects of extensive study in non-insulin dependent diabetes without a consistent abnormality being identified. ${ }^{36-38}$

We found that the offspring of hypertensive parents had reduced high density lipoprotein cholesterol concentrations. Several recent studies have supported the view that hypertensive patients often carry several risk factors for vascular disease and that these may have a familial component. ${ }^{0}{ }^{39}$ Reaven suggested that, because insulin resistance is associated with hypertension, hypertriglyceridaemia, and non-insulin dependent diabetes, it may contribute to the development of these abnormalities and, as a consequence, vascular disease..$^{40}$ This hypothesis remains controversial. ${ }^{41}$ Our data do not allow speculation beyond a role for insulin resistance in essential hypertension. It should be noted, however, that we excluded subjects with a family history of diabetes mellitus from our study, which would suggest that, if Reaven's view is correct, several different determinants of insulin action may be involved.

We have shown that insulin resistance is present at an early stage in the offspring of hypertensive parents and is associated with dyslipidaemia. The extent of insulin resistance in subjects with an increased risk of developing hypertension is similar to that in older patients with established clinical hypertension. It

\section{Clinical implications}

- Essential hypertension is associated with insulin resistance

- Offspring of hypertensive parents who are at increased risk of hypertension but who are not yet hypertensive show reduced insulin sensitivity compared with normotensive offspring of normotensive parents

- Insulin resistance precedes clinical hypertension and may be important in its aetiology

seems that the risk of a person developing essential hypertension is associated with reduced insulin sensitivity and that this may be determined in part by familial factors.

We thank Mr C N Ennis and Mr N P Bell for expert technical assistance, $\mathrm{Mr} C$ Patterson for statistical advice, and Mrs Marie Loughran for typing the manuscript. OLB was supported by a Royal Victoria Hospital Research Fellowship.

1 Shen DC, Shieh SM, Fuh MT, Wu DA, Chen YDI, Reaven GM. Resistance to insulin stimulated glucose uptake in patients with hypertension f Clin Endocrinol Metab 1988;66:580-3.

2 Swislocki AL, Hoffman BB, Reaven GM. Insulin resistance, glucose intolerance and hyperinsulinemia in patients with hypertension. $A m \mathcal{F}$ Hypertens 1989;2:419-23.

3 Modan M, Halkin H, Almog S, Lusky A, Eshkol A, Shefi M, et al. Hyperinsulinemia, a link between hypertension, obesity and glucose intolerance. F Clin Invest 1985;75:809-17.

4 Pollare T, Lithell H, Selinus I, Berne C. Application of prazosin is associated with an increase of insulin sensitivity in obese patients with hypertension. with an increase of insulin

5 Pollare T, Lithell H, Berne C. A comparison of the effects of hydrochlorthiazide and captopril on glucose and lipid metabolism in patients with hypertension. N Engl I Med 1989;321:868-73.

6 Pollare T, Lithell H, Selinus I, Berne C. Sensitivity to insulin during treatment with atenolol and metoprolol: a randomised, double blind study of effects of carbohydrate and lipoprotein metabolism in hypertensive patients. $B M \mathcal{J}$ 1989;298:1152-7.

7 Ferrannini E, Buzzigoli G, Bonadonna R, Giorico MA, Oleggini M, Graziadei $\mathrm{L}$, et al. Insulin resistance in essential hypertension. $N$ Engl $f \mathrm{Med}$ 1987;317:350-7.

8 Rooney DP, Neely RDG, Ennis CN, Bell NP, Sheridan B, Atkinson AB, et al. Insulin action and hepatic glucose cycling in essential hypertension. Metabolism 1992;41:317-24.

9 De Fronzo RA. The effect of insulin on renal sodium metabolism. Diabetologia 1981;21:165-71.

10 Rowe JW, Young JB, Minaker KL, Stevens AL, Pallotta J, Landsberg L. Effect of insulin and glucose infusions on sympathetic nervous system activity in normal man. Diabetes 1981;30:219-25.

11 Rooney DP, Edgar JDM, Sheridan B, Atkinson AB, Bell PM. The effects of low dose insulin infusions on the renin angiotensin and sympathetic nervous systems in normal man. Eur f Clin Invest 1991;21:430-5.

12 Stamler R, Stamler J, Riedlinger WF, Algera G, Roberts RH. Family (parental) history and prevalence of hypertension. FAMA 1979;241:43-6.

13 Watt G. Design and interpretation of studies comparing individuals with and without a family history of high blood pressure. $\mathcal{f}$ Hypertens 1986;4:1-7.

14 Munger RG, Prineas RJ, Gomez-Marin O. Persistent elevation of blood pressure among offspring with a family history of hypertension: the pressure among offspring with a family history of hypertension: the
Minneapolis offspring's blood pressure study. $f$ Hypertens 1988;6:647-53.

15 Challenge for the 90's-the change of hear baseline clinical survey. Belfast: Department of Epidemiological and Public Health, Queen's University of Department of Epidemiological and Public

16 Saltin B, Grimby G. Physiological analysis of middle-aged and old former athletes. Circulation 1968;381104-15.

17 Valdes CT, Elkind-Hirsch KE. Intravenous glucose tolerance test-derived insulin sensitivity changes during the menstrual cycle. $f$ Clin Endocrinol Metab 1991;72:642-6.

18 De Fronzo RA, Tobin JD, Andres R. Glucose clamp technique: a method for quantifying insulin secretion and resistance. Am $\mathcal{f}$ Physiol 1979;273: E214-23.

19 Hales CN, Randle PJ. Immunoassay of insulin with insulin antibody precipitate. Biochem F 1963;88:137-46.

20 Friedewald WT, Levy RI, Fredrickson DS. Estimation of the concentration of low-density lipoprotein cholesterol in plasma without the use of the preparative ultracentrifuge Clin Chem 1972;18:499-502.

21 Rizza RA, Mandarino LJ, Gerich JE. Mechanism and significance of insulin resistance in non-insulin-dependent diabetes mellitus. Diabetes 1981;30: $990-5$

22 Kolterman OG, Insel J, Saekow M, Olefsky JM. Mechanisms of insulin resistance in human obesity. Evidence for receptor and postreceptor defects. f Clin Invest 1980;65:1272-84

23 De Fronzo RA. Insulin secretion, insulin resistance and obesity. Int 9 Obes 1982;6(suppl 1):73-82.

24 Natali A, Santoro D, Palombo C, Cerri M, Ghione S, Ferrannini E. Impaired insulin action on skeletal muscle metabolism in essential hypertension. Hypertension 1991;17:170-8.

25 Laakso M, Edelman SV, Brechtel G, Baron AD. Decreased effect of insulin to stimulate skeletal muscle blood flow in obese man: a novel mechanism for insulin resistance. F Clin Invest 1990;85:1844-52.

26 Laakso M, Edelman S, Brechtel G, Baron A. Decreased insulin mediated 
glucose uptake (IMGU) in NIDDM subjects: the role of blood flow. Diabetes 1991;40(suppl 1):100A.

27 Ferrari P, Weidmann P, Shaw S, Giachino D, Riesen W, Allemann Y, et al Altered insulin sensitivity, hyperinsulinemia and dyslipidemia in individuals with a hypertensive parent. $A m$ f Med 1991;91:589-96.

28 Randle PJ, Garland PB, Hales CN, Newsholme EA. The glucose fatty acid cycle: its role in insulin sensitivity and the metabolic disturbances of diabetes mellitus. Lancet 1963:i:785-9.

29 Moore RD. Effects of insulin upon ion transport. Biochim Biophys Acta 1983;737:1-49.

30 Julius S, Gudbrandsson T, Jamerson K, Shahab ST, Andersson O. The haemodynamic link between insulin resistance and hypertension. 7 Hypertens 1991;9:983-6.

31 Williams RR, Hunt SC, Hasstedt SJ, Hopkins PN, Wu LW, Berry TD, et al. Current knowledge regarding the genetics of human hypertension. f Hypertens 1989;7(suppl 6):8-13.

32 Bogardus C, Lillioja S, Howard BV, Reaven G, Mott D. Relationships between insulin secretion, insulin action and fasting plasma glucose concentration in nondiabetic and non-insulin-dependent diabetic subjects. fClin Invest 1984; $74: 1238-46$.

33 Reaven G, Miller R. Study of the relationship between glucose and insulin responses to an oral glucose load in man. Diabetes 1968;17:560-9,

34 Bogardus C, Lillioja S, Nyomba BL, Zurlo F, Swinburn B, Esposito-Del Puente $A$, et al. Distribution of in vivo insulin action in Pima Indians as mixture of three normal distributions. Diabetes 1989;38:1423-32.
35 Lillioja S, Mott DM, Zawadzki JK, Young AA, Abbott WGH, Knowler WC, et al. In vivo insulin action is familial characteristic in nondiabetic Pima Indians. Diabetes 1987;36:1329-35.

36 Raben N, Barbetti F, Cama A, Lesniak MA, Lillioja S, Zimmet P, et al. Normal coding sequence of insulin gene in Pima Indians and Nauruans, two groups with highest prevalence of type II diabetes. Diabetes 1991;40: $118-22$.

37 Oelbaum RS, Bouloux PM, Li SR, Baroni MG, Stocks J, Galton DJ. Insulin receptor gene polymorphisms in type 2 (non-insulin-dependent) diabetes mellitus. Diabetologia 1991;34:260-4.

38 Kusari J, Berma US, Buse JB, Henry RR, Olefsky JM. Analysis of the gene sequences of the insulin receptor and the insulin sensitive glucose transporter (GLUT-4) in patients with common type non-insulin-dependen diabetes mellitus. $\mathcal{F}$ Clin Invest 1991;88:1323-30.

39 Williams RR, Hunt SC, Hopkins PN, Stults BM, Wu L, Hasstedt S, et al. Familial dyslipidemic hypertension: evidence from 58 Utah families for syndrome present in approximately $12 \%$ of patients with essential hypertension. FAMA 1988;259:3579-86.

40 Reaven GM. Role of insulin resistance in human disease. Diabetes 1988;37: 1595-607.

41 Jarrett RJ. In defence of insulin: a critique of syndrome X. Lancet 1992;340: 469-7

(Accepted 11 May 1993)

\title{
A decade of diabetes: keeping children out of hospital
}

\author{
P G F Swift, J R Hearnshaw, J L Botha, G Wright, N T Raymond, K F Jamieson
}

\begin{abstract}
Objectives-To document the number of children aged less than 15 years who developed diabetes and were managed within one large health district, and to evaluate the outcome of those children managed without hospital admission at diagnosis.

Design-A retrospective study over 1979-88, when a paediatrician and a physician with special interests in childhood diabetes initiated joint clinics. Data collected from the district diabetes register and files of consultants and health visitors specialising in diabetes.
\end{abstract}

Setting-Referral of children to consultants in Leicestershire (total population 863000 ).

Main outcome measures-The proportion of children managed without hospital admission, comparison of readmission rates and glycated haemoglobin concentrations between children admitted and those not admitted.

Results-Over 10 years 236 children aged 10-14 years developed diabetes (annual incidence rate $12 \cdot 8 / 100000$ child population $(95 \%$ confidence interval $11 \cdot 3$ to $14 \cdot 7)$ ). In total 138 were not admitted to hospital but received supervised management based at home. Admitted children were younger or acidotic or their family doctors did not contact the diabetes team. Duration of admission declined from seven days in 1979-80 to three days in 1987-8. Ninety two were not admitted to hospital during the 10 years for any reason. Significantly fewer children who received management at home were readmitted for reasons related to diabetes than the group treated in hospital $(30(22 \%) v 40(41 \%) ; p=0 \cdot 004)$. Concentrations of glycated haemoglobin were no different between the two groups.

Conclusions-Children with newly diagnosed diabetes may be safely and effectively managed out of hospital. Domiciliary or community based management depends on the commitment of consultants specialising in diabetes working in close cooperation with general practitioners, specialist nurses in diabetes, and dietitians.

\section{Introduction}

The United Kingdom has a comprehensive primary and community health care system, including the widespread availability of specialist nurses in diabetes in at least $81 \%$ of health districts. ${ }^{1}$ Yet children with newly diagnosed diabetes are still routinely admitted to hospital. ${ }^{2}$ The British Paediatric Association's working party on children's diabetes services found that $87 \%$ of paediatricians reported that virtually all children were admitted at the time of diagnosis. ${ }^{1}$ In 1988, 1600 children under 15 years of age living in the British Isles developed diabetes. ${ }^{3}$ A subsequent survey of these children confirmed that $95 \%$ were admitted to hospital, $42 \%$ for more than seven days. ${ }^{4}$ In the United States a position statement in 1990 by the American Diabetes Association accepted that inpatient care was most appropriate for children and adolescents when diabetes was diagnosed.

Supervised outpatient management of children was described over 40 years ago in the United Kingdom ${ }^{26}$ and since the $1970 \mathrm{~s}$ in Israel ${ }^{7}$ and the United States. There is no published work showing that hospital admission for children who do not require intravenous treatment is necessary or beneficial. Indeed several studies assume that there are benefits from a shorter duration of admission if the initiation of insulin treatment and basic education can be accomplished by an organised specialist team, ${ }^{1011}$ particularly when specialist nurses in diabetes are available..$^{11} 12$

The present study spanning the decade 1979-88 documents the number of children developing diabetes who were managed within a large NHS district (total population 863000); describes the management at diagnosis, drawing particular attention to the proportion of children not admitted to hospital; and evaluates the short and medium term efficacy of inpatient and outpatient management.

\section{Subjects and methods}

Names were identified of children aged 0-14 years who had developed insulin dependent diabetes between 1 January 1979 and 31 December 1988 from the Leicestershire diabetes register of all diabetic patients who were taking insulin (95-100\% complete for childhood diabetes ${ }^{13}$ ) and from consultants' card indexes. Data retrieved from the hospital notes of the children included date of diagnosis, age, duration of admission, where and by whom initially managed, readmissions to hospital, and reasons for readmissions. Analysis was made of all glycated haemoglobin concentrations during the 10 years of study. Compari- 